\title{
ÁREAS DE PRESERVAÇÃO PERMANENTE E CONFLITOS AMBIENTAIS NO MUNICÍPIO DE BARÃO DE COTEGIPE (RS): UMA ANÁLISE COM AUXÍLIO DAS GEOTECNOLOGIAS*
}

\author{
AREAS OF PERMANENT PRESERVATION AND ENVIRONMENTAL CONFLICTS \\ IN THE MUNICIPALITY OF BARAO DE COTEGIPE (RS): AN ANALYSIS WITH \\ THE USE OF GEOTECHNOLOGIES
}

\author{
ÁREAS DE CONSERVACIÓN PERMANENTE Y LOS CONFLICTOS \\ AMBIENTALES EN LA CIUDAD DE BARÃO DE COTEGIPE (RS): UN ANÁLISIS \\ CON EL AUXILIO DE GEOTECNOLOGÍA
}

\author{
Franciele Francisca Marmentini Rovani - Universidade Federal de Santa Maria \\ - Santa Maria - Rio Grande do Sul - Brasil \\ franciele.rovani@yahoo.com.br
Roberto Cassol - Universidade Federal de Santa Maria
- Santa Maria - Rio Grande do Sul - Brasil
rtocassol@gmail.com

\section{Resumo}

0 espaço geográfico, resultado de contínuas transformações, apresenta seu ambiente natural fragilizado, por causa, sobretudo, do uso inadequado da terra, da degradação de ecossistemas florestais e da devastação de áreas de vegetação nativa e de preservação permanente. Atualmente, a utilização das geotecnologias tem contribuído significativamente para a identificação e delimitação dessas áreas fragilizadas, para posterior implementação de ações de planejamento e gestão ambiental. Deste modo, a presente pesquisa objetivou analisar 0 uso da terra, as áreas de preservação permanente (APPs) e as áreas de conflitos com APPs nos anos de 2000 e 2010, no município de Barão de Cotegipe (RS), por meio de técnicas de Sensoriamento Remoto e dos Sistemas de Informações Geográficas (SIGs). Para a elaboração dos mapas temáticos utilizaram-se imagens de satélite e a programação em LEGAL no software Spring versão 5.0.6. Como resultado, verificou-se que os principais usos da terra são de culturas agrícolas e florestas. As APPs representaram $12,77 \%$ da área total do município, no entanto, nos anos de 2000 e 2010, mais da metade dessas áreas, 7,80\% e 7,31\% respectivamente, estavam em conflitos com áreas agricultáveis e campos. Esses resultados apontam a falta de preservação das áreas protegidas por lei, bem como a sua degradação. Ações de planejamento e gestão ambiental no município podem minimizar os impactos causados pela dinâmica da ação humana no meio.

Palavras-chave: áreas de preservação permanente, uso da terra, geotecnologias, planejamento ambiental.

\section{Abstract}

The geographic space, result of continues changes; represent a natural and undermined environment related to the inadequate use of soil, degradation of forest ecosystems, devastation of native vegetation and permanent preservation. Nowadays, the use of geo-technologies has contributed significantly in the identification and delimitation of these undermined areas to subsequent implementation in actions of environmental planning and management systems. In this way, the present research aim at analyze the use of soil in permanent preservation

\footnotetext{
* Auxílio do Programa de Bolsas de Iniciação Científica da Universidade Federal de Santa Maria, do tipo FIPE Sênior.
} 
areas (PPAs) and the conflict areas of PPAs from the year 2000 to the year 2010, in the city of Barão de CotegipeRS, with techniques of Remote Sensing of Geographic . In order to draw the thematic maps, satellites images and programming in LEGAL in the software Spring version 5.0.6 were used. As a result, the main use of soil and agriculture culture and forest. The PPAs represent $12,7 \%$ of the total areas of the city, however, from the year 2000 and 2010 , more than a half of this areas, $7,80 \%$ and 7,31\% respectively, were in conflict with agriculture and field areas. These results show the lack of preservation of protective law areas, as well as their degradation. Plan action and environmental management in the city can minimize impacts caused by the dynamic of human action in the area.

Keywords: permanent preservation areas, use of soil, geotechnologies, environmental plan.

\section{Resumen}

El espacio geográfico, resultado de continuas transformaciones, presenta su medio ambiente natural debilitado, debido principalmente al mal uso de la tierra, la degradación de los ecosistemas forestales, destrucción de la vegetación autóctona y áreas de preservación permanente. En la actualidad, el uso de geotecnologías ha contribuido significativamente en la identificación y delimitación de las áreas vulnerables para promover la aplicación de la planificación y gestión ambiental. Por lo tanto, este trabajo analiza el uso de la tierra, las áreas de preservación permanente (APPs) y las áreas de conflicto con las APPs en los años 2000 y 2010 en el municipio de Barão de Cotegipe-RS por medio de técnicas de Sensores Remotos y Sistemas de Información Geográfica. Para la elaboración de mapas temáticos fueron utilizadas imágenes de satélite y la programación LEGAL del software Spring, versión 5.0.6. Como resultado, se encontró que los principales usos de la tierra son los cultivos agrícolas y florestales. Las APPs representan $12,77 \%$ de la superficie total del municipio, sin embargo, en los años 2000 y 2010, más de la mitad de estas áreas, $7,80 \%$ y $7,31 \%$ respectivamente, estaban en conflicto con las áreas agrícolas y campos. Estos resultados indican la falta de conservación de las áreas protegidas por ley, así como la degradación de las mismas. La planificación de acciones y la gestión ambiental en el municipio puede reducir al mínimo los impactos causados por la dinámica de la acción humana en el medio.

Palabras clave: áreas de preservación permanente, uso de la tierra, geotecnología, planificación ambiental.

\section{Introdução}

As transformações espaciais ocorridas ao longo do tempo, influenciadas, sobretudo, pelas atividades humanas, têm-se tornado cada vez mais perceptíveis. A busca pela ocupação do espaço e, consequentemente, o uso dos recursos naturais de maneira imprópria resultam em alterações ecológicas e espaciais. Na visão de Santos (1997), o espaço é um fator da evolução social, contudo, não é formado apenas pelas coisas, os objetos geográficos, naturais e artificiais, presentes na natureza. Além do meio natural e artificial, o espaço geográfico é constituído também pela sociedade.

O uso inadequado da terra, a degradação de ecossistemas florestais são resultados de processos contínuos, principalmente de ações antrópicas, no espaço geográfico. A devastação de áreas de vegetação nativa e de preservação permanente resulta em desequilíbrios naturais. As áreas de preservação permanente (APPs) definidas pelo Código Florestal Brasi- 
leiro (Brasil, 1965), posteriormente consideradas reservas ecológicas pela Lei n. 6.938 (Brasil, 1981), representam locais de grande risco a possíveis impactos ambientais, quando utilizadas para fins agrícolas, industriais, de ocupação urbana e outros.

Deste modo, as relações entre o homem e o meio, entre o social e o espacial estão estritamente interligadas e constituem parte integrante dos estudos territoriais. O planejamento ambiental surgiu a partir das últimas três décadas, em razão da competição pelo uso drástico dos recursos naturais e também como resposta adversa ao desenvolvimento tecnológico, de caráter puramente materialista. Para Silva (2009), o planejamento ambiental refere-se a um processo de pensar e estruturar possibilidades que levem ao gerenciamento de diversas ordens (econômica, social, política, cultural e natural). Esse processo permite dar racionalidade às ações, buscando ordenar os conflitos e diminuir as desigualdades socioeconômicas e os impactos ambientais.

Corroborando com essa ideia, Santos (2004, p. 24) destaca que o planejamento

é um processo contínuo que envolve a coleta, organização e análise sistematizada das informações, por meio de procedimentos e métodos, para chegar a decisões ou a escolhas acerca das melhores alternativas para o aproveitamento dos recursos disponíveis.

O planejamento implica decidir sobre ações futuras que visem ao ordenamento das atividades humanas, por meio de técnicas e decisões.

A prática da análise ambiental, como ferramenta de apoio à decisão e ao fornecimento das informações imprescindíveis às decisões político-administrativas concernentes aos recursos ambientais (Silva; Souza, 1987), é uma perspectiva destacada quanto à identificação dos conflitos ambientais. O desenvolvimento de diagnósticos e prognósticos locais ou regionais que visem a auxiliar no planejamento requer "compreender em escalas diversas as inter-relações dos sistemas ambientais, bem como a magnitude dos fenômenos naturais ou induzidos, sua abrangência geográfica, suas implicações diretas e a propagação dos seus efeitos no tempo e no espaço" (Ronchi; Coelho; Gomes, 2003, p. 13).

Para consolidar ações de planejamento em estudos do espaço geográfico, especialmente o ambiental, merecem destaque as técnicas de análise, que, associadas à organização das informações com uso das tec- 
nologias, constituem instrumentos importantes para efetivar a atualização de dados e gerar bancos de dados geográficos para uso dos órgãos municipais. Deste modo, ações de planejamento podem vir a ser desenvolvidas pelo poder público, com o intuito de recuperar áreas degradadas e/ ou preservar áreas naturais.

Neste sentido, o avanço de técnicas computacionais e sistemas de informações permitem a identificação e a delimitação de inúmeros dados, naturais ou artificiais. O uso de geotecnologias, dentre as quais os Sistemas de Informações Geográficas (SIGs), o Sensoriamento Remoto, tem se mostrado eficaz quando empregados para a delimitação de APPs (Almeida; Berger, 2007). Destacam-se, ainda, por ser um conjunto de tecnologias destinadas à coleta e ao tratamento de informações espaciais.

Os SIGs, uma tecnologia integradora, permitem a análise dos sistemas naturais e sociais com maior precisão e eficácia (Rosa, 2004). Assim, com o auxílio deles, torna-se possível obter documentos cartográficos que possibilitam a visualização, a comunicação e o estudo integrado dos dados. Como exemplo, têm-se os mapas temáticos que visam o mapeamento de fenômenos físicos e culturais, incluindo distâncias e direções, padrões de localização ou atributos espaciais de mudanças, de tamanho e magnitude (Dent, 1996).

Deste modo, os municípios, de modo especial e independentemente de sua extensão territorial e constituição socioeconômica, devem utilizar os diagnósticos e os planos como ferramentas essenciais para a gestão dos seus recursos. Embasados nessas premissas, objetivou-se analisar as conformações ambientais do espaço geográfico do município de Barão de Cotegipe (RS), por meio da análise do uso e ocupação da terra, das APPs e das áreas de conflitos com as APPs nos anos de 2000 e 2010, utilizando as técnicas de Sensoriamento Remoto e de Geoprocessamento.

\section{Área de estudo}

O município de Barão de Cotegipe encontra-se localizado na porção norte do estado do Rio Grande do Sul, entre as coordenadas geográficas $27^{\circ} 28^{\prime}$ a $27^{\circ} 39^{\prime} \mathrm{S}$ e $52^{\circ} 20^{\prime}$ a $52^{\circ} 31^{\prime} \mathrm{W}$ (Figura 1). Possui uma área territorial de $360 \mathrm{~km}^{2}$ e altitude média aproximada de 870 metros em relação ao nível do mar.

Situa-se na região geomorfológica denominada Planalto, na zona de Campeamento Basalto-Arenítico do Paraná, caracterizada por dois domí- 
nios topográficos distintos: ao sul, planalto de ondulações suaves, e ao norte, um reentalhamento constituído por vales encaixados e vertentes abruptas com afloramentos basálticos conhecidos por "peraus" (Piran, 1982). Quanto à vegetação, o município encontra-se na área pertencente ao bioma Mata Atlântica, em que predomina a Floresta Ombrófila Mista (Floresta das Araucárias) e a Floresta Estacional Decidual (Floresta Subtropical do Alto Uruguai).

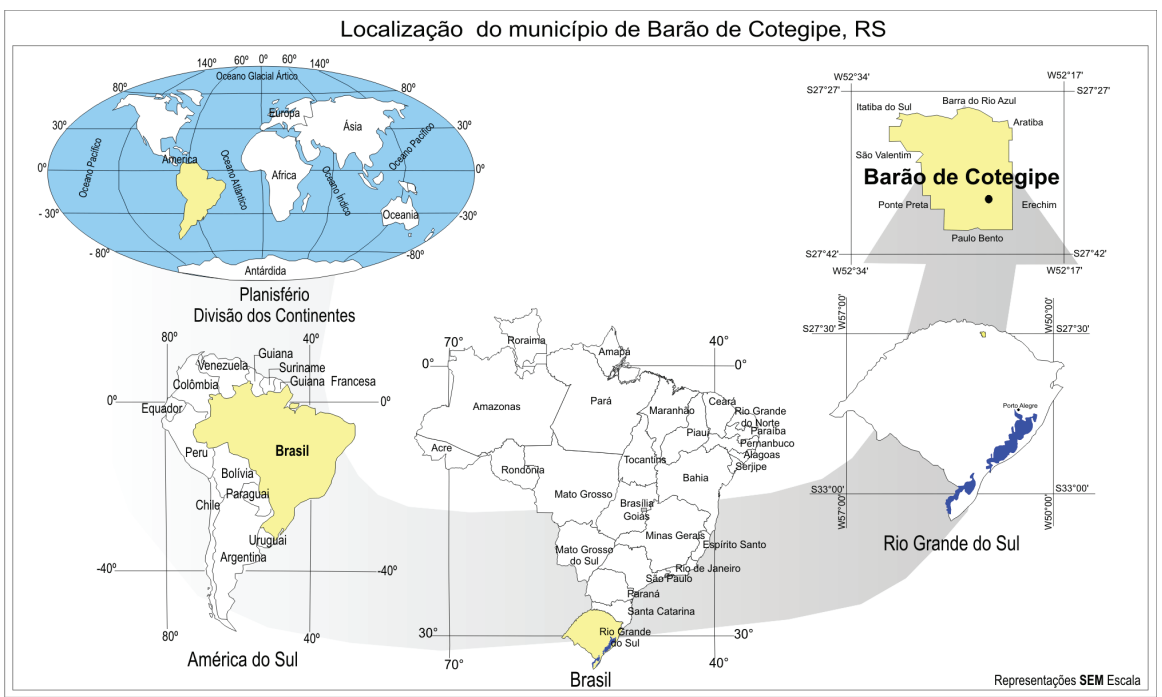

FIGURA 1- Mapa de localização do município de Barão de Cotegipe (RS)

Fonte: Adaptado de Moreira (2009).

A base econômica municipal é constituída principalmente pelo setor primário. Na agropecuária destaca-se a produção de bovinos, aves e suínos. Já na agricultura, o predomínio das pequenas propriedades favoreceu o desenvolvimento da agricultura familiar com a produção majoritariamente de milho $(52,7 \%)$ e soja $(36,5 \%)$, seguida pelas culturas de feijão, trigo e arroz, segundo o censo agropecuário (IBGE, 2006).

Base de dados e mapas temáticos

Para o desenvolvimento desta pesquisa foram utilizados dados cartográficos (cartas topográficas) e imagens de satélite para a elaboração dos 
mapas temáticos de uso e ocupação da terra, APPs e áreas de conflitos, bem como observações na Legislação Ambiental, conforme o diagrama (Figura 2).

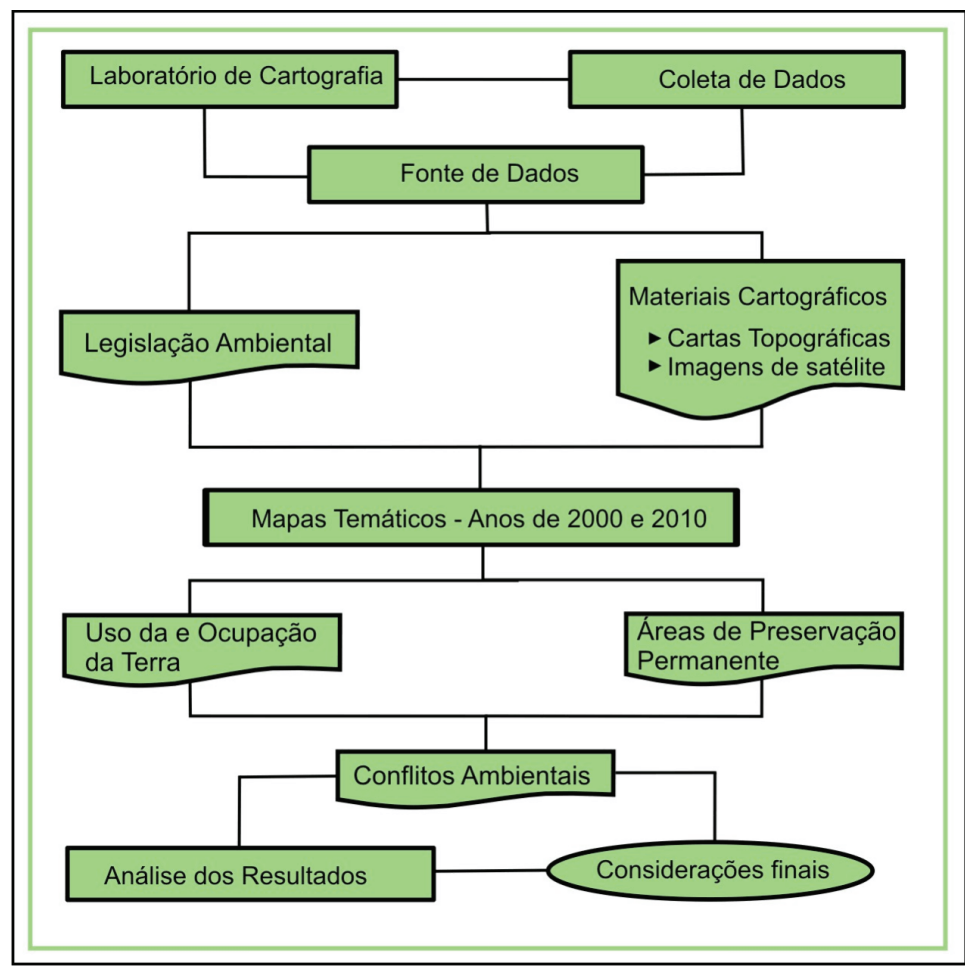

FIGURA 2 - Diagrama dos procedimentos desenvolvidos na pesquisa Fonte: Adaptado de Rovani (2010).

Inicialmente elaborou-se a base cartográfica do município de Barão de Cotegipe, utilizando as quatro cartas topográficas, na escala 1:50000, disponibilizadas pela $1^{\mathrm{a}}$ Divisão de Levantamento ( $\left.1^{\mathrm{a}} \mathrm{DL}\right)$, que compreendem o território municipal: Aratiba - Folha SG.22-Y-D-I-3, Campinas do Sul - Folha SG.22-Y-C-VI-2, Erexim - Folha SG.22-Y-D-VI-1 e Erval Grande - Folha SG.22-Y-C-III-4. Elas foram editadas e vetorizadas no software Sistema de Processamento de Informações Georreferenciadas (Spring), versão 5.0.6, disponibilizado pelo Instituto Nacional de Pesquisas Espaciais (INPE). 
Foram elaborados os mapas temáticos de uso e ocupação da terra para os anos de 2000 e 2010, o mapa de áreas de preservação permanente (APPs) e os mapas de conflitos com APPs para os anos de 2000 e 2010.

Para a elaboração dos mapas de uso e ocupação da terra, adquiriram-se no INPE as imagens de satélite Landsat-5 referentes aos anos de 2000 e 2010, órbita 222, ponto 79, bandas 3, 4 e 5. As imagens adquiridas foram selecionadas seguindo o critério da menor presença de nuvens e, deste modo, dataram de 13 de maio de 2000 e 18 de fevereiro de 2010. O período compreende as estações de verão e outono, de poucas chuvas, predomínio da colheita de grãos e preparo para as culturas de inverno, o que favoreceu a análise dos dados.

Com o auxílio do software Spring, utilizou-se o modo de classificação não supervisionada, por meio do classificador Maxver. Definiram-se cinco classes representativas de uso (Tabela 1).

TABELA 1 - Classes consideradas para a elaboração do mapa de uso e ocupação da terra do município de Barão de Cotegipe (RS)

\begin{tabular}{|c|l|}
\hline Classes & Definição \\
\hline 1 & Água - todos os corpos hídricos \\
\hline 2 & Área urbanizada - área que compreende o perímetro urbano municipal \\
\hline 3 & Culturas - áreas agricultáveis com predomínio de lavouras implantadas \\
\hline 4 & Florestas - compreendem todas as áreas florestais naturais ou implantadas \\
\hline 5 & $\begin{array}{l}\text { Solo exposto - áreas destinadas à agricultura em situação de preparo ou em } \\
\text { pousio }\end{array}$ \\
\hline
\end{tabular}

Fonte: Rovani (2010).

O mapa das APPs foi elaborado tendo-se como referência o Código Florestal (Brasil, 1965, 1989), a Política Nacional do Meio Ambiente (Brasil, 1981) e as disposições sobre os parâmetros, definições e limites das APPs (Brasil, 2002). É importante salientar que, sob a ótica da legislação ambiental, a proteção dos elementos ambientais abióticos (água, ar e solo) e bióticos (fauna e flora) é de fundamental importância para a conservação da biodiversidade do planeta. O Código Florestal Federal possibilita determinar as áreas que deveriam ser protegidas, para a manutenção do equilíbrio natural, o ciclo vital e a qualidade de vida de todas as espécies, bem como das fontes de recursos hídricos. 
Com base nestas premissas, identificaram-se quatro classes de áreas de preservação permanente, representadas pelo modo de implantação zonal e da variável visual cor (Tabela 2).

TABELA 2 - Classes consideradas para a elaboração do mapa de áreas de preservação permanentes (APPs) do município de Barão de Cotegipe (RS)

\begin{tabular}{|c|l|}
\hline Classes & Definição \\
\hline 1 & Declividades maiores que $25^{\circ}$ \\
\hline 2 & APPs - Nascentes \\
\hline 3 & APPs - Margem de rios \\
\hline 4 & APPs - Topo de morros e montanhas \\
\hline
\end{tabular}

Fonte: Rovani (2010).

As APPs nas margens dos rios foram delimitadas em uma faixa marginal de trinta metros para os cursos d'água com menos de dez metros de largura; as APPs em nascentes, identificadas com um raio mínimo de cinquenta metros; as APPs em topos de morros e montanhas, definidas a partir da curva de nível correspondente a dois terços da altura mínima da elevação em relação à base e as APPs nas encostas ou parte destas, com declividade superior a $45^{\circ}$, correspondente a $100 \%$, na linha de maior declive. Em função da inadequação da base cartográfica utilizada (escala 1:50000) não foi possível avaliar as áreas com declive igual ou superior a $45^{\circ}$. Assim, foram mapeadas as áreas com declive superior a $25^{\circ}$ (47\%), não sendo necessariamente consideradas APPs, porém, com restrições de uso, impossibilidade de corte raso da vegetação e extração somente de toras de maneira racional, de acordo com o artigo $10^{\circ}$ do Código Florestal.

Por fim, foram elaborados os mapas de conflitos de uso da terra com as APPs, resultado da integração do mapa das APPs com os mapas de uso da terra para 2000 e 2010, por meio da programação de Linguagem Espacial para Geoprocessamento Algébrico (LEGAL). A representação dos mapas deu-se pelo modo de implantação zonal e a variável visual cor (Tabela 3). 
TABELA 3 - Classes consideradas para a elaboração do Mapa de Conflitos do município de Barão de Cotegipe (RS)

\begin{tabular}{|c|l|}
\hline Classes & Cruzamento \\
\hline \multirow{3}{*}{1} & $\begin{array}{l}\text { Declividade }>25^{\circ} \text { / Culturas } \\
\text { APP }- \text { Margem de rios / Culturas } \\
\text { APP }- \text { Nascentes / Culturas } \\
\text { APP }- \text { Topo de morros / Culturas }\end{array}$ \\
\hline \multirow{3}{*}{2} & $\begin{array}{l}\text { APP - Declividade }>25^{\circ} \text { / Solo exposto } \\
\text { APP }- \text { Margem de rios / Solo exposto } \\
\text { APP }- \text { Nascentes / Solo exposto } \\
\text { APP }- \text { topo de morros / Solo exposto }\end{array}$ \\
\hline 3 & $\begin{array}{l}\text { APP }- \text { Margem de rios / Áreas urbanizadas } \\
\text { APP - Nascentes / Áreas urbanizadas }\end{array}$ \\
\hline
\end{tabular}

Fonte: Rovani (2010).

\section{Resultados e discussão}

A análise dos resultados obtidos por meio da representação em mapas para os anos de 2000 e 2010 permitiu verificar um processo de transformação do espaço geográfico do município em função das diferentes relações entre a sociedade e o meio. As diversas formas de organização espacial, sobretudo das áreas rurais, e as interferências antrópicas são fatores significativos das alterações no município.

O mapa das APPs, obtido por meio das observações na Legislação, apresenta aquelas áreas que deveriam ser protegidas para a manutenção do equilíbrio natural, do ciclo vital e da qualidade de vida de todas as espécies, bem como das fontes de recursos hídricos (Figura 3).

Observando o mapa da Figura 3, identificam-se três classes de APPs e uma classe de restrição de uso, compreendendo um total de 3325,22 ha, ou seja, 12,77\% da área municipal. As APPs nas margens dos rios destacaram-se em área de abrangência em relação às demais $(68,99 \%)$, visto que o município possui uma vasta rede hidrográfica. As APPs em nascentes (5,78\%) foram delimitadas com um raio de 50 metros de abrangência e estão diretamente associadas à rede de drenagem.

As APPs em topos de morros e montanhas apresentam-se em segunda maior proporção $(16,56 \%)$ e estão situadas, sobretudo, nas áreas com declividades superiores a $15^{\circ}$ e com altitudes acima de 750 metros. Já as áreas com declividades acima de $25^{\circ}$ representam $(8,67 \%)$ da área total das APPs, localizadas principalmente em altitudes superior a 850 metros. 


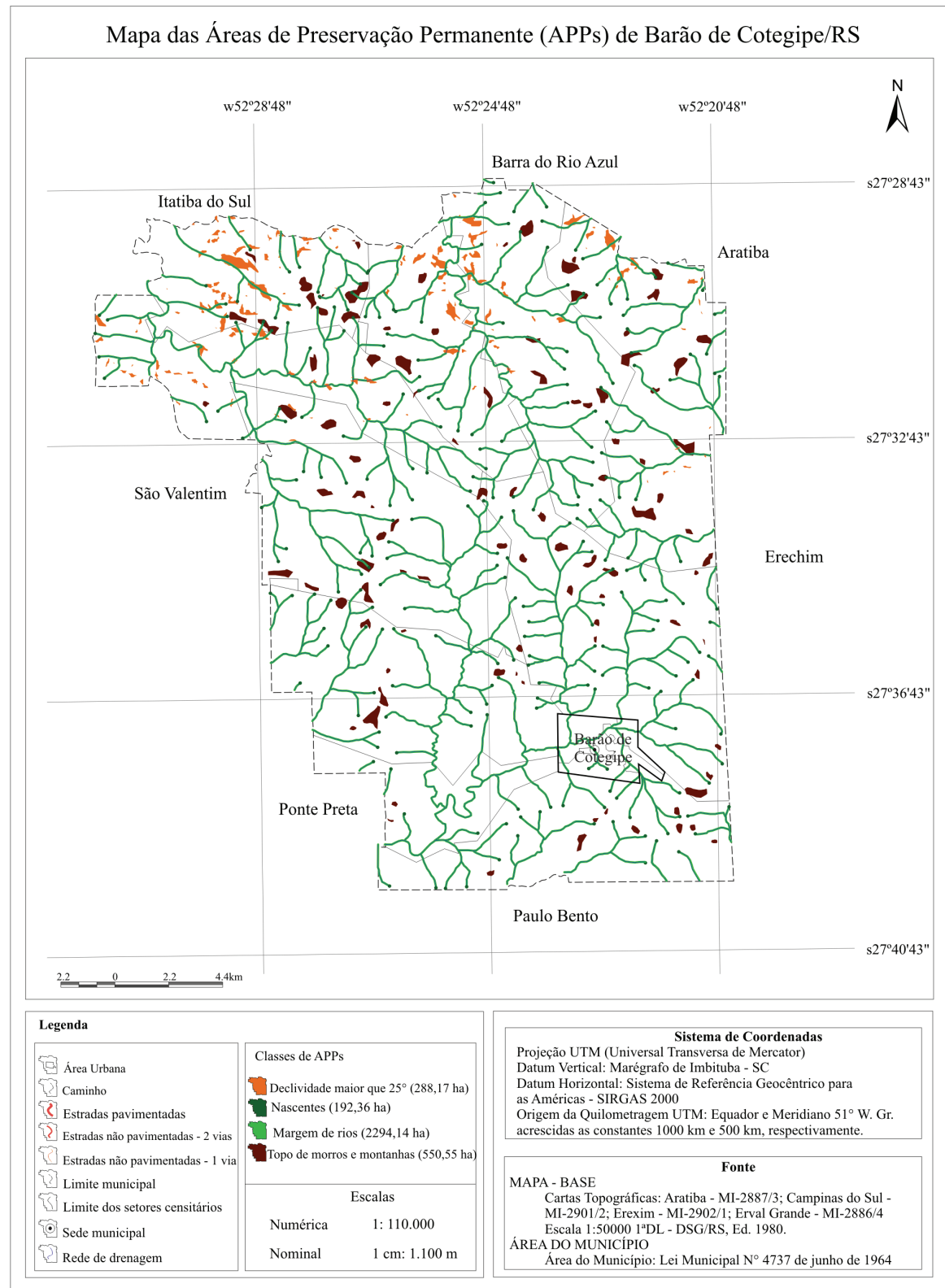

FIGURA 3 - Mapa das áreas de preservação permanente (APPs) do município de Barão de Cotegipe (RS)

Fonte: Rovani (2010). 
Nessas áreas não é permitida a mecanização da agricultura nem a urbanização, sendo esse o limite para corte raso, a partir do qual a exploração só é liberada se sustentada à cobertura de florestas.

Essas áreas definem os pontos estratégicos que deveriam ser protegidos para a manutenção do equilíbrio natural, da harmonia e preservação do meio ambiente. A Tabela 4 apresenta o total da área ocupada por cada classe de uso nos anos de 2000 e 2010, em hectares e percentagem.

TABELA 4 - Uso e ocupação da terra em 2000 e 2010 em hectares e percentagem no município de Barão de Cotegipe (RS)

\begin{tabular}{|c|c|c|c|c|}
\hline \multirow{2}{*}{ Uso da terra } & \multicolumn{2}{|c|}{2000} & \multicolumn{2}{|c|}{2010} \\
\hline & Área (ha) & Área (\%) & Área (ha) & Área (\%) \\
\hline Água & 21,96 & 0,09 & 50,83 & 0,20 \\
\hline Área urbanizada & 441,09 & 1,69 & 441,09 & 1,69 \\
\hline Culturas & 12319,75 & 47,31 & 11298,24 & 43,39 \\
\hline Florestas & 8991,28 & 34,53 & 10019,79 & 38,47 \\
\hline Solo exposto & 4264,92 & 16,38 & 4229,05 & 16,25 \\
\hline Total & 26039,00 & 100 & 26039,00 & 100 \\
\hline
\end{tabular}

Fonte: Rovani (2010).

As Figuras 4 e 5 representam a espacialização do uso e ocupação da terra nos anos 2000 e 2010, obtida com base na classificação das imagens de satélite. Esses mapas mostram que os usos que mais se destacaram foram as culturas anuais, compreendendo as áreas com agricultura implantada. Essas áreas incluem o cultivo temporário dos principais produtos agrícolas, como o milho, o trigo e a soja, significativamente. Compreendem também as áreas com cultivo de erva-mate e os pomares, em especial parreiras e laranjas.

Com base na Tabela 4 e na Figura 4, verificou-se que as áreas de solo exposto, compreendendo as áreas em pousio ou em preparo para a implantação de culturas, com os campos, representaram 16,38\% da área total. A base econômica do município é a agricultura e, por isso, essas áreas encontram-se em constantes rotações, isto é, oscilam as culturas de inverno e de verão com plantios diretos e indiretos. As florestas, ou seja, as áreas com matas nativas ou exóticas, destacaram-se, sobretudo, na porção norte do município (34,53\%), nas margens de alguns rios e nas encostas de morros, o que indica em parte a sua preservação. Os corpos 


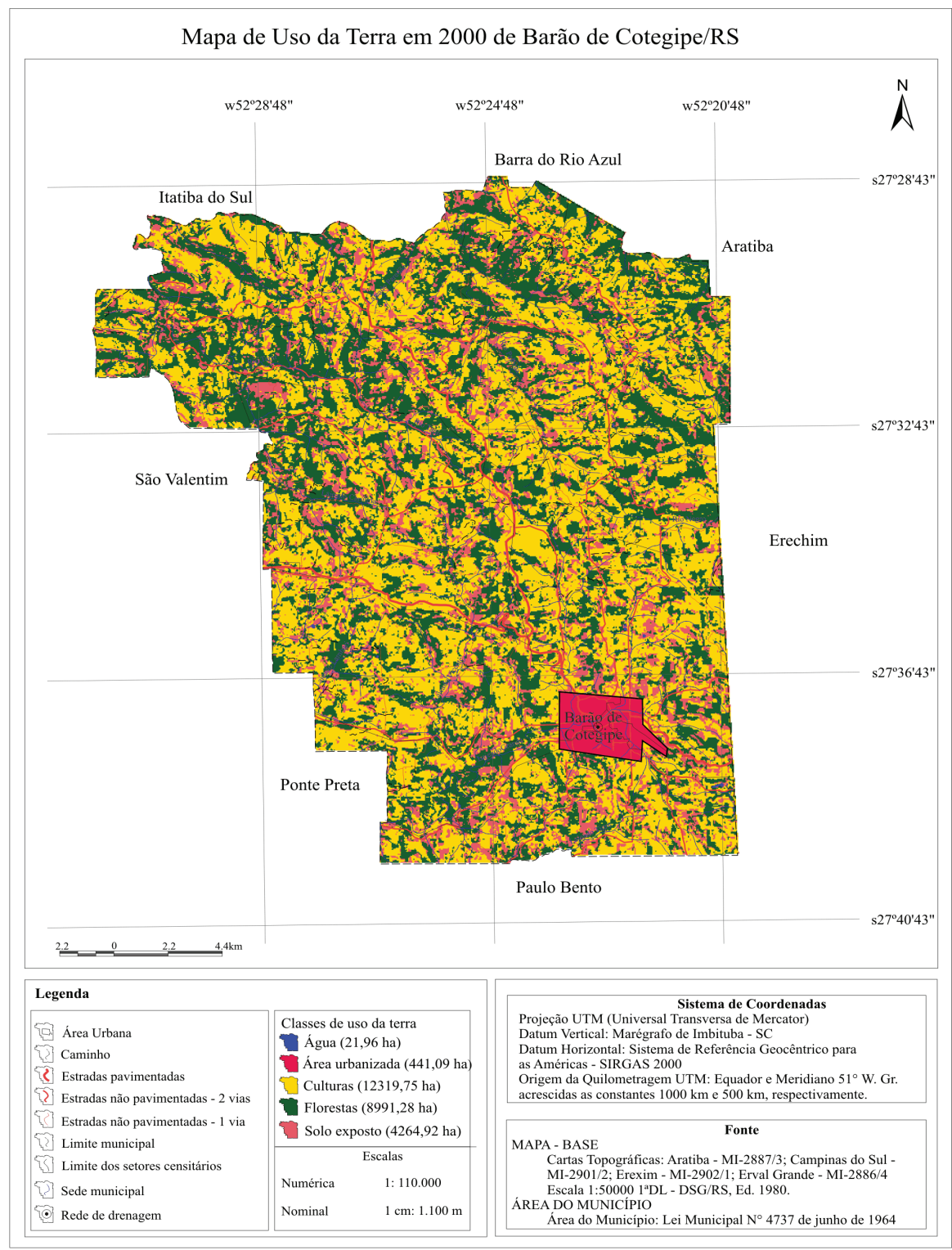

FIGURA 4 - Mapa de uso e ocupação da terra em 2000 no município de Barão de Cotegipe (RS) Fonte: Rovani (2010). 


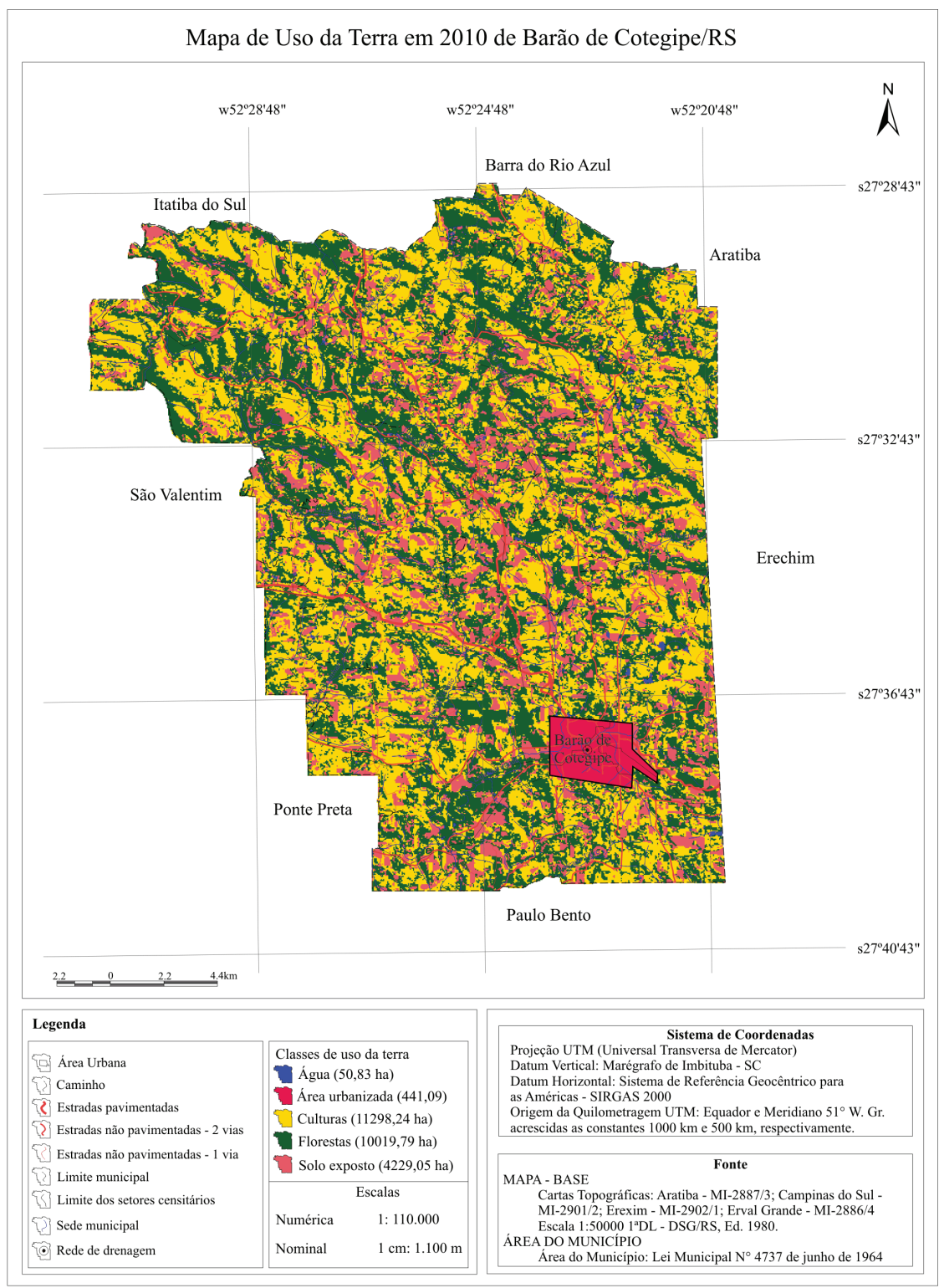

FIGURA 5 - Mapa de uso e ocupação da terra em 2010 do município de Barão de Cotegipe (RS) Fonte: Rovani (2010). 
hídricos compreenderam 0,09\% da área total, representando os lagos artificiais, os reservatórios e os rios.

Com relação ao uso da terra em 2010, notaram-se algumas mudanças significativas, se comparadas com a análise do uso em 2000. De acordo com a Figura 5, identificaram-se mudanças relativas aos usos: água, culturas, solo exposto e florestas. Um aumento significativo dos corpos hídricos $(0,11 \%)$ deve-se especialmente à instalação de novos reservatórios e lagos artificiais destinados à piscicultura. As áreas florestais também apresentaram um expressivo aumento, passando de $34,53 \%$ para $38,47 \%$ da área total. Esse fato deve-se ao incentivo de novos reflorestamentos, com a instalação de áreas florestadas com fins principalmente de caráter econômico.

As culturas, bem como as áreas com solo exposto, alteraram entre si, visto que há uma dependência entre elas. Nesta análise, como já foi citado, identificaram-se as áreas de solo exposto como sendo as áreas em preparo para plantio, em pousio ou, ainda, os campos. Dependendo da data da imagem ou do período em que foi analisada, haverá uma variação entre as classes, oscilando entre áreas em preparo para culturas e áreas já agricultáveis. As áreas urbanas, tomadas como base a referência dos setores censitários, não apresentaram mudanças.

Da análise das APPs com o uso e ocupação da terra em 2000 e 2010, têm-se a atual situação dos conflitos ambientais para esse período (Figuras 6 e 7 ).

Em relação às áreas de conflitos de uso da terra (Figuras 6 e 7), constatou-se que os usos como áreas urbanas, culturas e solo exposto estão conflitando com as áreas de APPs em declividades maiores de $25^{\circ}$, em topos de morros e montanhas, em nascentes e nas margens dos rios. Esses conflitos representam de maneira significativa a influência da ação humana nos recursos naturais e a falta de preocupação com a preservação e manutenção das áreas protegidas por lei. Além disso, o uso indevido da terra nas APPs resulta no empobrecimento da rede hidrográfica, nos processos de lixiviação, de erosão e nas diversas formas de poluição.

Analisando as áreas de conflitos de uso da terra para o ano de 2000, pode-se verificar que, no perímetro urbano, as nascentes e as margens de rios não estão sendo protegidas, ou seja, a área que compreende essas APPs está comprometida com as áreas urbanas. As áreas conflitantes com o uso de solo exposto compreendem 555,57 hectares, ou seja, 2,13\%, e as áreas conflitantes com o uso de culturas representam 5,46\% da área total 


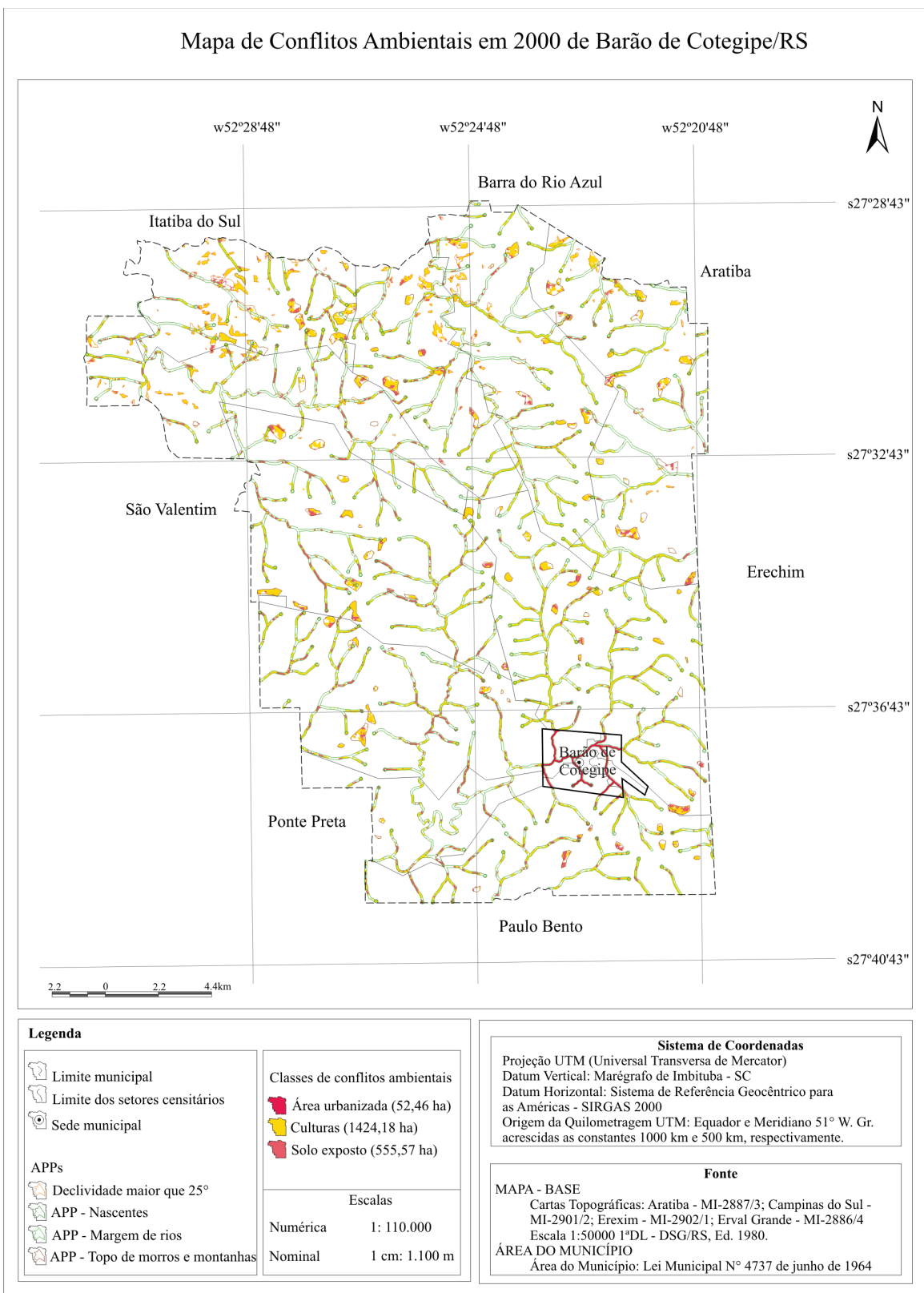

FIGURA 6 - Mapa de Conflitos Ambientais em 2000 do município de Barão de Cotegipe (RS) Fonte: Rovani (2010). 


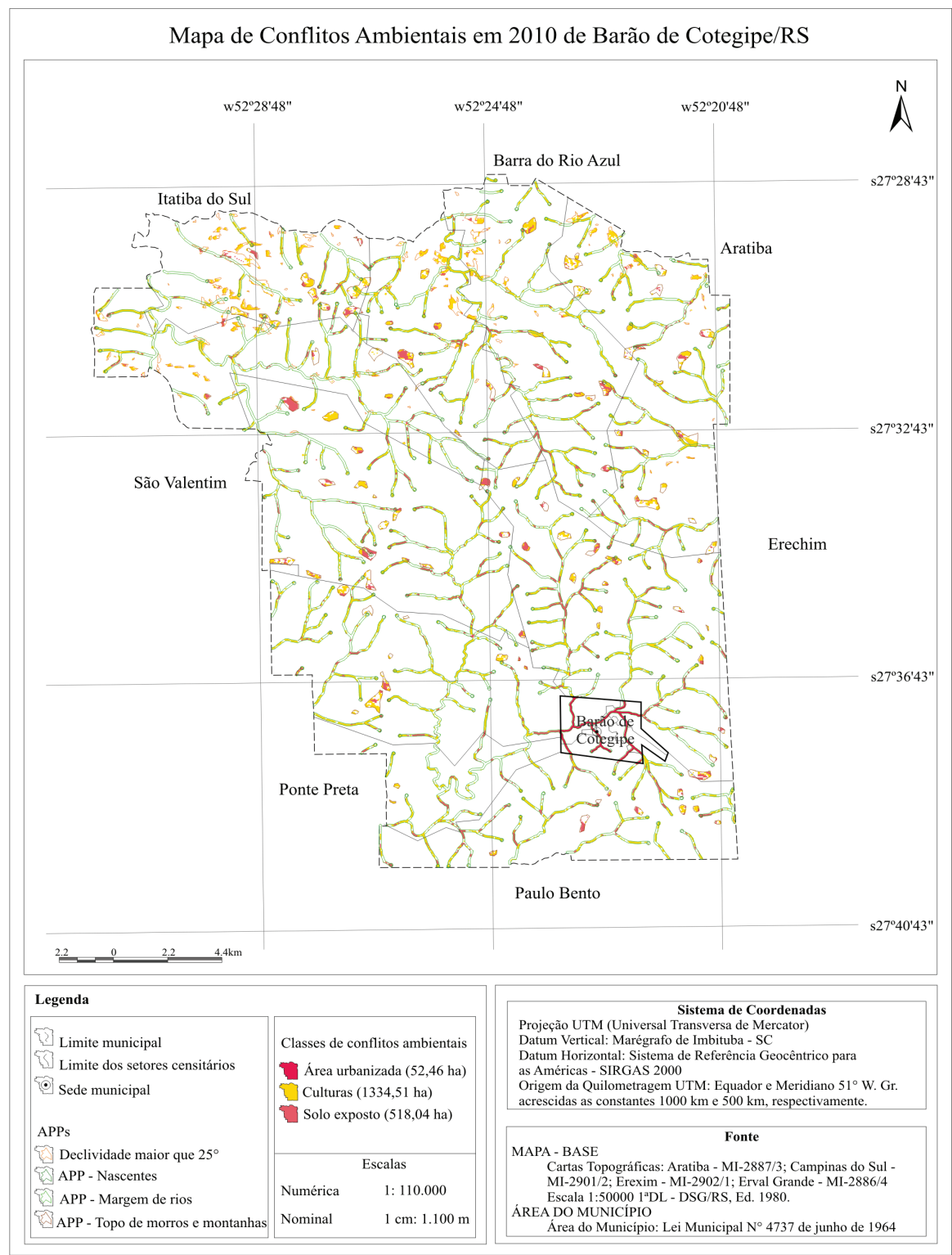

FIGURA 7 - Mapa de Conflitos Ambientais em 2010 do município de Barão de Cotegipe (RS) Fonte: Rovani (2010). 
do município. Destaca-se que os conflitos com o uso de solo exposto e de culturas encontram-se distribuídos em todas as classes de APPs.

No ano de 2010 (Figura 7), as áreas de conflitos apresentaram uma pequena redução se comparadas com o ano de 2000, com exceção dos conflitos referentes ao uso da área urbana. As áreas conflitantes com o uso do solo exposto passaram de 555,57 para 518,04 hectares, enquanto as áreas conflitantes com o uso das culturas passaram de 1424,18 para 1334,51 hectares, com uma redução de 89,67 hectares de área. Isto significa que houve uma pequena mudança no que diz respeito à proteção das APPs, sobretudo aquelas situadas nas margens de rios e nos topos de morros e montanhas, visto que no mesmo período houve um aumento das áreas com florestas.

A Figura 8 apresenta uma comparação entre o uso e a ocupação da terra, bem como das áreas de conflitos com APPs, nos anos de 2000 e 2010.

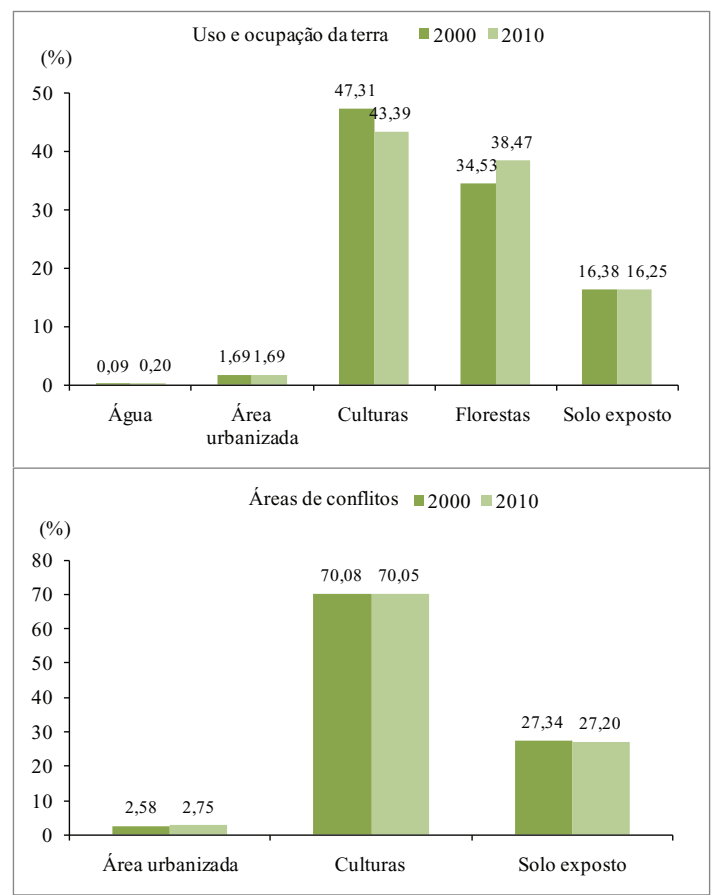

FIGURA 8 - Comparação entre o uso e ocupação da terra e das áreas de conflitos com APPS nos anos de 2000 e 2010 
Observando-se a Figura 8, verificou-se que as maiores alterações do uso e ocupação da terra nesses anos de análise deram-se em relação às classes de culturas e florestas, em que houve um incremento destas últimas em 2010. As áreas de conflitos apresentaram pequenas mudanças pontuais, mas, se comparadas à área total de conflitos entre 2000 e 2010, nota-se que houve uma diminuição de 127,19 ha. Esses números apontam que algumas áreas passaram então a ser preservadas, ainda que em pequena proporção.

\section{Considerações finais}

A análise do espaço geográfico de Barão de Cotegipe permitiu diagnosticar as transformações e/ou modificações espaciais decorrentes dos agentes naturais e da ação humana a partir de 2000 até 2010. As técnicas empregadas possibilitaram atender os objetivos propostos de modo eficaz.

As áreas de preservação permanente representaram 12,77\% da área total, no entanto, no ano de 2000, verificou-se que as áreas conflitantes somaram 7,80\% e no ano de 2010, totalizaram 7,31\% em relação à área total do município, ou seja, mais da metade das áreas que deveriam estar protegidas estavam sendo degradadas pelos usos indevidos. As mudanças ocorridas nesse período, principalmente com relação ao uso da terra e às áreas de conflito ambiental, representam a dinâmica entre a ação humana e o meio.

A análise realizada possibilitará auxiliar nas tomadas de decisões em setores estratégicos do município, bem como contribuirá para que ações de desenvolvimento já iniciadas possam ser difundidas em todo território, proporcionando aos gestores municipais mais iniciativas de planejamento e ordenamento espacial.

Assim, a tomada de ação de gestores municipais diretamente nos locais mais críticos, por meio de projetos ou de parcerias, poderá minimizar os impactos ambientais, sobretudo com relação aos corpos hídricos e nas encostas ou topos de morros. As decisões a serem tomadas deverão ser elaboradas em conjunto, de modo que o planejamento ambiental no município possa ser participativo e vise a sustentabilidade ambiental e a qualidade do ambiente. 


\section{Referências}

ALMEIDA, A. Q. de; BERGER, B. Comparação entre áreas de preservação permanente demarcadas a partir de diferentes escalas topográficas. In: MORAIS, A. C. de; SANTOS, A. R. dos. (Org.). Geomática e análise ambiental. Vitória: EDUFES, 2007. p. 19-39.

BRASIL. Lei Federal n. 4.771, de 15 de setembro de 1965. Institui o novo Código Florestal. Brasília, 15 set. 1965.

BRASIL. Lei Federal n. 6.938, de 31 de agosto de 1981. Dispõe sobre a política Nacional do Meio Ambiente, seus fins e mecanismos de formulação e aplicação, e dá outras providências. Brasília, 31 ago. 1981.

BRASIL. Lei Federal n. 7.803, de 18 de julho de 1989. Altera a redação da Lei n. 4.771, de 15 de setembro de 1965, e revoga as leis n. 6.535, de 15 de junho de 1978, e 7.511, de 7 de julho de 1986. Brasília, 18 jul. 1989.

BRASIL - Conselho Nacional do Meio Ambiente - CONAMA. Resolução n. 303, de 20 de março de 2002. Dispõe sobre parâmetros, definições e limites de áreas de Preservação Permanente. Disponível em: <http://www.mma.gov.br/conama/>. Acesso em: 3 fev. 2010.

DENT, B. D. Cartography: thematic map design. 4. ed. Chicago, USA: Wm C. Brown Publishers (WCB), 1996.

IBGE. Instituto Brasileiro de Geografia e Estatística. Censo Agropecuário 2006. Disponível em: <http://www.sidra.ibge.gov.br/bda/acervo/acervo1.asp?ti=1\&tf=9 9999\&e $=\mathrm{v} \& \mathrm{t}=1 \& \mathrm{p}=\mathrm{CA} \& \mathrm{z}=\mathrm{t} \& \mathrm{o}=3>$. Acesso em: 12 ago. 2010.

MOREIRA, A. Planejamento ambiental do município de Barra Bonita, SC, na perspectiva das tecnologias de informação geográfica. Dissertação (Mestrado em Geografia) - Departamento de Geociências, Universidade Federal de Santa Maria, Santa Maria, RS, 2009.

PIRAN, N. A pequena produção rural em Erechim: um estudo de caso. Dissertação (Mestrado em Geografia) - Instituto de Geociências e Ciências Exatas, Universidade Estadual Paulista “Júlio de Mesquita Filho”, Rio Claro, SP, 1982.

ROSA, R. Sistema de informação geográfica. Minas Gerais: Ed. UFU, 2004.

RONCHI, L. H.; COELHO, O. G. W.; GOMES, L. P. Tecnologia, diagnóstico e planejamento ambiental. In: RONCHI, L. H.; COELHO, O. G. W. (Org.). Tecnologia, diagnóstico e planejamento ambiental. São Leopoldo (RS): Unisinos, 2003. p. 13-16.

ROVANI, F. F. M. Análise sócio-ambiental de Barão de Cotegipe-RS, sob a ótica das tecnologias de informação geográfica. Monografia (Graduação em Geografia) - Departamento de Geociências, Universidade Federal de Santa Maria, Santa Maria, RS, 2010.

SANTOS, M. Espaço e método. 4. ed. São Paulo: Nobel, 1997. 
Franciele Francisca Marmentini Rovani - Mestranda em Geografia pela Universidade Federal de Santa Maria.

Roberto Cassol - Doutor em Geografia pela Universidade de São Paulo - Professor da Universidade Federal de Santa Maria.

Recebido para publicação em junho de 2012

Aceito para publicação em setembro de 2012 